\title{
MEDIASI KEPUASAN KERJA ANTARA PENGEMBANGAN KARIR DAN KINERJA PERAWAT RUMAH SAKIT UMUM DAERAH ABDUL WAHAB SJAHRANIE SAMARINDA
}

\author{
Edi Sukamto1), Rasmun'2), Sutrisno) \\ 1,2,3Poltekkes Kemenkes Kalimantan Timur, Samarinda \\ Email : edidiharjo2@gmail.com
}

\begin{abstract}
Achievement of optimal performance can be done if nurses have career development and competence, besides that nurse satisfaction is also a determining factor in Nurse performance. The purpose of this study was to determine the effect of career development and competence on job satisfaction and performance. The population in this study was the Staff Nurses. The sampling technique is Saturated Sampling (Sensus). The sample in this study were all staff nurses who worked in the inpatient ward of the AWS Samarinda regional general hospital, totaling 201 staff nurses. This research was analyzed using the SmartPLS program. The results of this study indicate that career development has a positive and significant effect on job satisfaction, competence has a positive and not significant effect on job satisfaction, career development has a positive and not significant effect on nurse performance, competence has a positive and significant effect on performance, job satisfaction has a positive and significant effect on Nurses performance, job satisfaction has mediates between career development and performance on Nurses AWS Samarinda regional general hospital.
\end{abstract}

Keywords: Career Development, Competence, Satisfaction, Nurse Performance

\begin{abstract}
Abstrak
Pencapaian kinerja yang optimal dapat dilakukan apabila perawat mempunyai pengembangan karir dan kompetensi, selain itu kepuasan perawat juga menjadi faktor penentu kinerja Perawat. Tujuan dalam penelitian ini adalah untuk mengetahui pengaruh pengembangan karir dan kompetensi terhadap kepuasan kerja dan kinerja. Populasi dalam penelitian ini adalah Perawat Pelaksana. Teknik pengambilan sampel adalah Saturated Sampling (sensus). Sampel pada penelitian ini adalah seluruh perawat yang bekerja di ruang rawat inap rumah sakit umum daerah Abdul Wahab Sjahranie Samarinda, yang berjumlah 201 perawat pelaksana. Penelitian ini dianalisis dengan menggunakan program SmartPLS. Hasil penelitian ini menunjukkan pengembangan karir berpengaruh positif dan signifikan terhadap kepuasan kerja, kompetensi berpengaruh positif dan tidak signifikan terhadap kepuasan kerja, pengembangan karir berpengaruh positif dan tidak signifikan terhadap kinerja Perawat, kompetensi berpengaruh positif dan signifikan terhadap kinerja, kepuasan kerja berpengaruh positif dan signifikan terhadap kinerja Perawat, kepuasan kerja mampu memediasi antara pengembangan karir dan kinerja Perawat RSUD Abdul Wahab Sjahranie Samarinda.
\end{abstract}

Kata Kunci: Pengembangan Karir, Kompetensi, Kepuasan, Kinerja Perawat

PENDAHULUAN

Rumah Sakit Umum Daerah
(RSUD) membutuhkan sosok perawat yang mau dan mampu melakukan pekerjaan lebih dari sekadar tugas formalnya dan mau 
memberikan kinerja yang melebihi harapan. Perawat dengan kemampuan seperti ini cukup langka, padahal perawat menginginkan kinerja lebih baik untuk melaksanakan tugas pokok dan fungsinya di daerah. Dalam dunia kerja yang dinamis seperti saat ini, yang mana tugas makin sering dikerjakan dalam tim, fleksibilitas sangatlah penting. Untuk itu organisasi menginginkan karyawan yang bersedia melakukan tugas yang tidak tercantum dalam deskripsi pekerjaannya.

Penilaian suatu kinerja dan kepuasan dalam suatu organisasi, termasuk RS banyak ditentukan oleh keberhasilan pengembangan karir yang diterapkan dalam menghasilkan kinerja. Pengembangan karir mempunyai peranan penting untuk mencapai tujuan suatu organisasi. Keberadaan pengembangan karir juga diperlukan untuk meningkatkan kinerja sumber daya manusia, selain pengembangan karir kompetensi juga mempunyai peran penting dalam peningkatan kepuasan kerja dan kinerja. Kompetensi dapat diartikan sebagai kemampuan seseorang yang dapat terobservasi mencakup atas pengetahuan, keterampilan dan sikap dalam menyelesaikan suatu pekerjaan atau tugas dengan standar kinerja (performance) yang ditetapkan. Standar kompetensi perawat merefleksikan atas kompetensi yang diharapkan dimiliki oleh individu yang akan bekerja di bidang pelayanan keperawatan di Rumah Sakit Umum Daerah Abdul wahab Sjahranie (RSUD AWS) Samarinda

Berdasarkan uraian latar belakang masalah yang telah dikemukakan, maka masalah yang dapat dirumuskan pada penelitian ini adalah: 1) Apakah pengembangan karir berpengaruh terhadap kepuasan kerja Perawat RSUD AWS Samarinda? 2) Apakah kompetensi berpengaruh terhadap kepuasan kerja Perawat RSUD AWS Samarinda? 3) Apakah pengembangan karir berpengaruh terhadap kinerja Perawat RSUD AWS Samarinda? 4) Apakah kompetensi berpengaruh terhadap kinerja Perawat RSUD AWS Samarinda? 5) Apakah kepuasan kerja berpengaruh terhadap kinerja Perawat RSUD AWS Samarinda?

\section{METODE PENELITIAN}

Jenis penelitian ini merupakan penelitian eksplanatori dengan pendekatan cross sectional. Pada penelitian ini populasinya adalah seluruh perawat di ruang rawat inap RSUD AWS Samarinda yang keseluruhannya berjumlah 201 perawat. Sampel pada penelitian ini adalah perawat di 10 ruang rawat inap RSUD AWS Samarinda. Untuk pengambilan sampel, penulis menggunakan penelitian populasi yaitu semua responden dijadikan sampel dalam penelitian. Berdasarkan sampel keseluruhan tersebut, maka jumlah sampel dalam penelitian ini adalah sebanyak 201 perawat. Metode analisa data yang 
digunakan dalam penelitian ini, yaitu analisis deskriptif dan statistika inferensial dengan SmartPLS. Kelebihan PLS adalah kemampuannya memetakan seluruh jalur ke banyak variabel dependen dalam satu model penelitian yang sama dan menganalisis semua jalur dalam model struktural secara simultan.

HASIL PENELITIAN

Karakteristik responden

Karakteristik responden penelitian ini mengenai pengembangan karir, kompetensi terhadap kepuasan kerja dan kinerja perawat di RSUD Abdul Wahab Sjahranie Samarinda yang menggambarkan identitas responden berdasarkan jenis kelamin, usia, status pernikahan, pendidikan terakhir, status kepegawaian dan masa kerja dari Perawat di ruang rawat inap RSUD Abdul Wahab Sjahranie Samarinda. Dari responden sebanyak 201 responden, maka deskripsi karakteristik responden sebagai berikut:

Tabel 1. Karakteristik Responden Penelitian

\begin{tabular}{lcc}
\multicolumn{1}{c}{ Karakteristik Responden } & Jumlah & Persentase \\
\hline Jenis kelamin & & \\
1) Laki-laki & 70 & $35 \%$ \\
2) Perempuan & 131 & $65 \%$ \\
Usia responden & & \\
1) <20 tahun & 10 & $5 \%$ \\
2) $21-40$ tahun & 96 & $48 \%$ \\
3) 40-60 tahun & 95 & $47 \%$ \\
Status Pernikahan & & \\
1) Belum Menikah & 64 & $32 \%$ \\
2) Menikah & 121 & $60 \%$ \\
3) Duda / Janda & 16 & $8 \%$ \\
Pendidikan Terakhir & & \\
1) D-3 Keperawatan & 129 & $64 \%$ \\
2) D-4 Keperawatan & 40 & $16 \%$ \\
3) S-1 Kep Ners & 32 & \\
Status Kepegawaian & & $65 \%$ \\
1) PNS & 131 & $35 \%$ \\
2) Honorer & 70 & \\
Lama Bekerja kerja & & $9 \%$ \\
1) <1 Tahun & 18 & $32 \%$ \\
2) 1-5 Tahun & 64 & $47 \%$ \\
3) 6-10 Tahun & 94 & $5 \%$ \\
4) 11-20 Tahun & 10 & $7 \%$ \\
5) > 20 Tahun & 15 & \\
& 201 & \\
\hline Jumlah & & \\
\hline
\end{tabular}

Sumber: Data Primer, Diolah Penulis 2020.

Dari Tabel menunjukkan bahwa sebagian besar responden 
penelitian ini adalah jenis kelamin perempuan yaitu sebanyak 131 orang atau 65\%. Karakteristik penelitian berdasarkan jenis kelamin lebih didominasi oleh perempuan, hal ini sesuai dengan jumlah Perawat di ruang rawat inap RSUD AWS, yang kebanyakkan adalah perempuan. Berdasarkan usia responden menunjukkan bahwa responden penelitian ini paling banyak berusia dari 21 sampai dengan 40 tahun yaitu sebanyak 96 orang atau 48\%. Kondisi ini memberikan gambaran bahwa Perawat di ruang rawat inap RSUD AWS banyak diisi oleh pegawai yang berusia dari 21 sampai dengan 40 tahun. Berdasarkan status perkawinan menunjukkan bahwa responden penelitian ini paling banyak berstatus menikah yaitu sebanyak 121 orang atau $60 \%$. Kondisi ini memberikan gambaran bahwa Perawat di ruang rawat inap RSUD AWS banyak diisi oleh pegawai yang telah menikah.

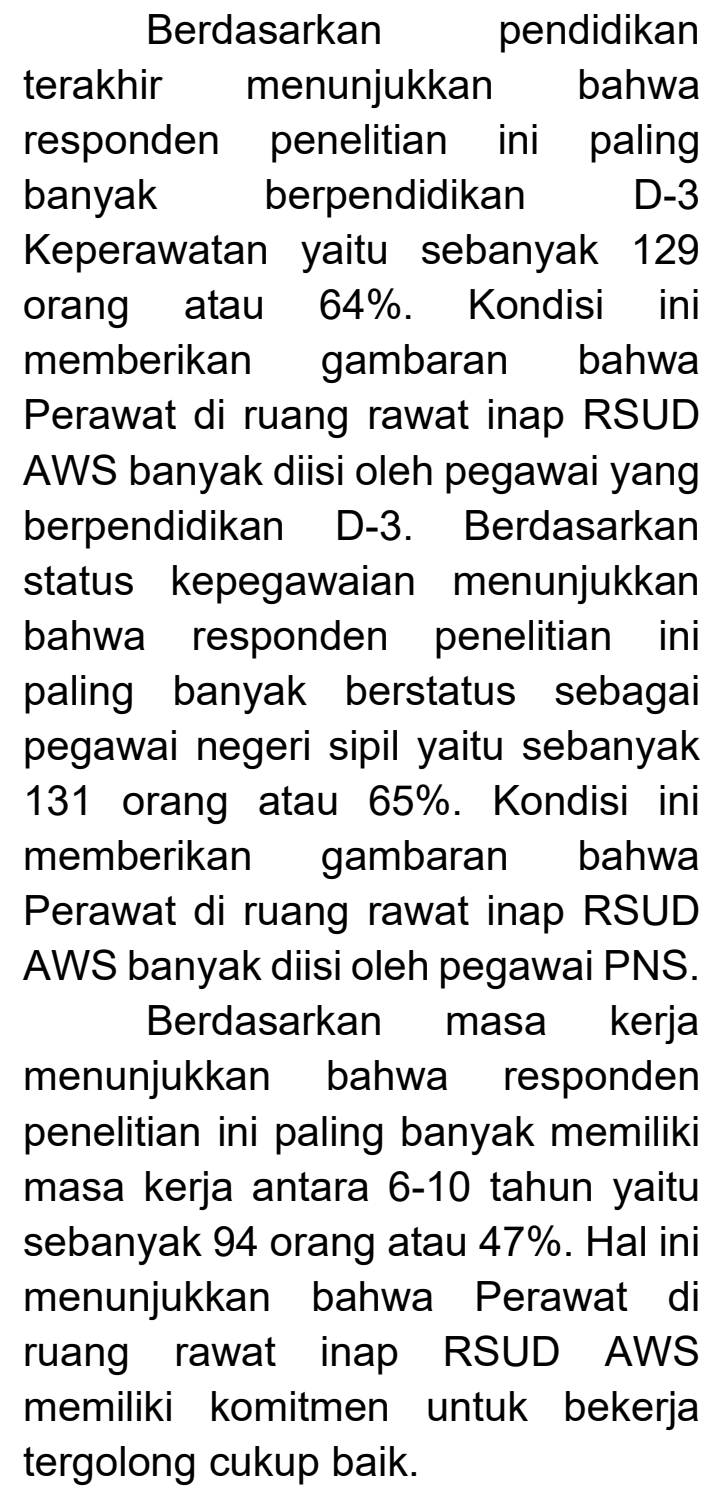

Berdasarkan pendidikan terakhir menunjukkan bahwa responden penelitian ini paling Keperawatan yaitu sebanyak 129 orang atau 64\%. Kondisi ini memberikan gambaran bahwa Perawat di ruang rawat inap RSUD AWS banyak diisi oleh pegawai yang berpendidikan D-3. Berdasarkan status kepegawaian menunjukkan bahwa responden penelitian ini paling banyak berstatus sebagai pegawai negeri sipil yaitu sebanyak 131 orang atau 65\%. Kondisi ini Perawat di ruang rawat inap RSUD AWS banyak diisi oleh pegawai PNS. Berdasarkan masa kerja menunjukkan bahwa responden penelitian ini paling banyak memiliki sebanyak 94 orang atau 47\%. Hal ini menunjukkan bahwa Perawat di ruang rawat inap RSUD AWS tergolong cukup baik. 


\section{Model Hubungan antar Variabel}

Tabel 2. Dasar Teori dalam Pengembangan Kerangka Konseptual

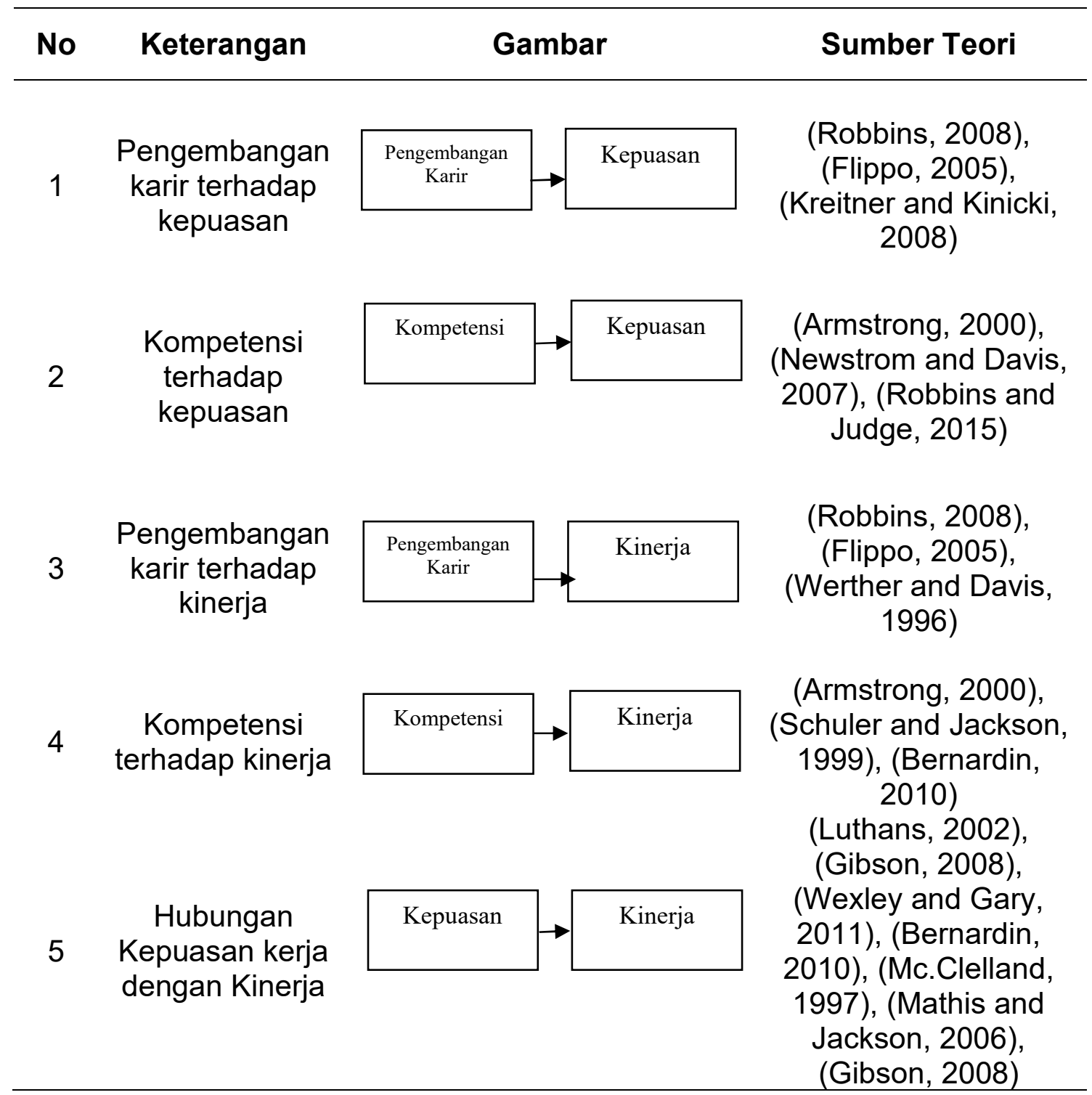

Sumber: Teori-teori dari berbagai sumber 
Model Penelitian dengan Menggunakan Partial Least Square (PLS)

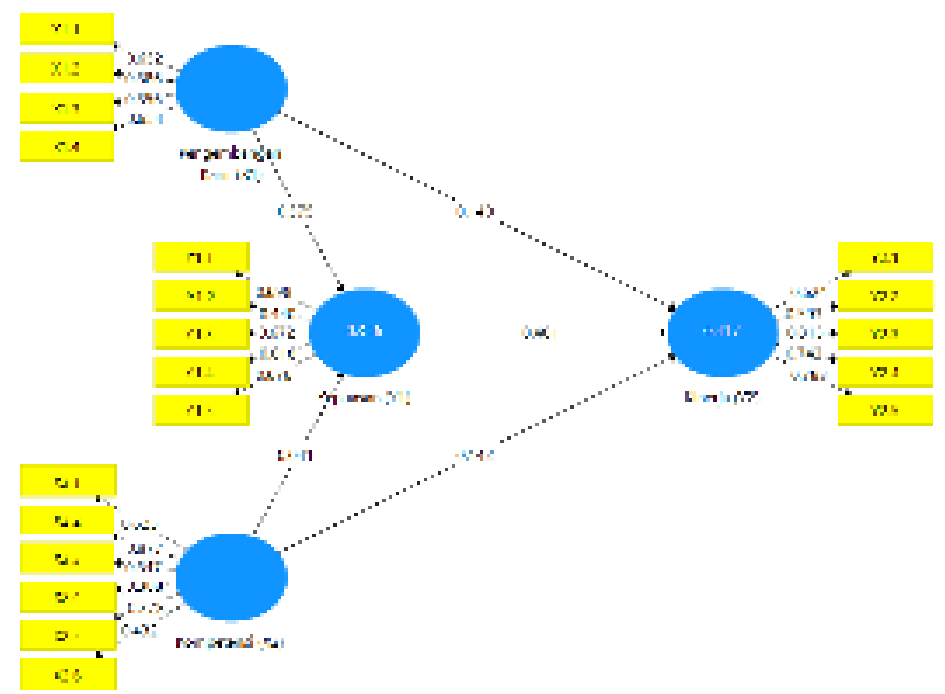

Gambar 1. Model Penelitian (Eliminasi I)

Pada model penelitian, syarat penelitian mula-mula adalah loading factor di atas 0,50 indikator $\mathrm{X}_{2.4}, \mathrm{X}_{2.5}, \mathrm{X}_{2.6}, \mathrm{Y}_{1.2}$ diperoleh mencerminkan loading factor yang model penelitian yang baru dengan menggambarkan variabel. Indikator gambar sebagai berikut: yang dieliminasi dalam model

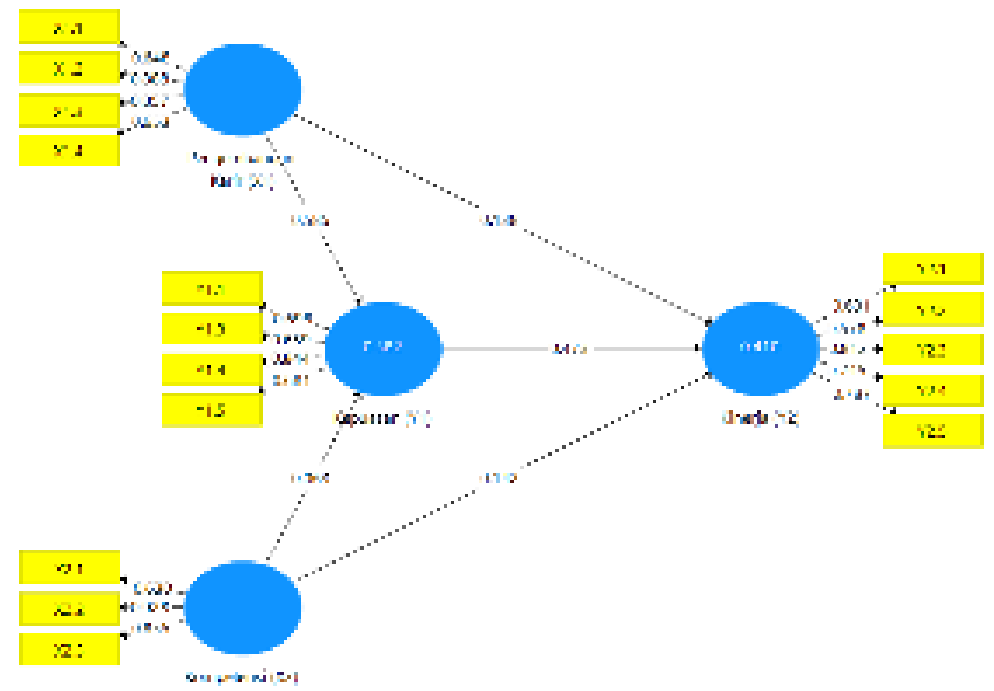

Gambar 2. Model Penelitian yang Baru

Berdasarkan gambar semua loading factor nilainya di atas 0,50 sehingga penelitian dapat dilanjutkan untuk menganalisis model pengukuran atau outer model dan model structural atau inner model.

\section{Pengujian t-test}

Persamaan

struktural menjelaskan pengaruh variabel eksogen terhadap variabel endogen, 
terdapat dua fungsi eksogen dalam model penelitian, yang dapat terhadap endogen yang dijelaskan dilihat pada Tabel sebagai berikut:

Tabel 3. Results for Inner Weights

\begin{tabular}{lccc}
\hline & $\begin{array}{c}\text { Original } \\
\text { Sample }\end{array}$ & $\begin{array}{c}\mathrm{t}- \\
\text { statistik }\end{array}$ & $\mathrm{p}$-Value \\
\hline $\begin{array}{l}\text { Pengembangan karir } \\
\text { berpengaruh terhadap kepuasan } \\
\text { perawat }\end{array}$ & 0,585 & 11,686 & 0,000 \\
$\begin{array}{l}\text { Kompetensi berpengaruh } \\
\text { terhadap kepuasan perawat }\end{array}$ & 0,063 & 0,799 & 0,425 \\
$\begin{array}{l}\text { Pengembangan karir } \\
\text { berpengaruh terhadap kinerja }\end{array}$ & 0,138 & 1,935 & 0,054 \\
$\begin{array}{l}\text { perawat } \\
\text { Kompetensi berpengaruh } \\
\text { terhadap kinerja perawat }\end{array}$ & 0,142 & 2,038 & 0,042 \\
$\begin{array}{l}\text { Kepuasan kerja berpengaruh } \\
\text { terhadap kinerja perawat }\end{array}$ & 0,473 & 6,224 & 0,000 \\
\hline
\end{tabular}

Sumber: Output SmartPLS

Berdasarkan Tabel maka dapat diketahui pengaruh positif dan tingkat signifikansi masing-masing variabel, apabila $\mathrm{P}$-Value $<0,05$ berarti variabel eksogen memberikan pengaruh signifikan terhadap variabel endogen dan apabila P-Value $>0,05$.

\section{Pengaruh tidak Langsung (Indirect Effects)}

Tabel 4. Pengaruh Tidak Langsung (indirect effects)

\begin{tabular}{ccc}
\hline No & Variabel & Indirect Effect \\
& Nilai \\
\hline & $\begin{array}{c}\text { Pengembangan karir } \\
\text { terhadap kinerja melalui } \\
\text { kepuasan }\end{array}$ & Nilai koefisien $=0,277$ \\
& & Nilai T-Statistics $=5,350>1,96$ \\
& Nilai P-Values $=0,000<0,05$ \\
& (positif dan signifikan) \\
2 & Kompetensi terhadap kinerja & Nilai koefisien $=0,030$ \\
& melalui kepuasan & Nilai T-Statistics $=0,759<1,96$ \\
& Nilai P-Values $=0,448>0,05$ \\
& (positif dan tidak signifikan)
\end{tabular}

Sumber: Output SmartPLS

Berdasarkan tabel pengaruh tidak langsung (indirect effects) dapat diketahui pengaruh tidak langsung yang dapat diidentifikasi sebagai berikut:
1) Pengaruh tidak langsung pengembangan karir terhadap kinerja melalui kepuasan memberikan pengaruh positif signifikan, artinya kepuasan dalam pengaruhnya telah 


\section{mampu sebagai variabel intervening antara pengembangan karir terhadap kinerja. \\ 2) Pengaruh tidak langsung kompetensi terhadap kinerja melalui kepuasan memberikan pengaruh positif tidak signifikan, artinya kepuasan dalam pengaruhnya belum mampu sebagai variabel intervening antara kompetensi dan kinerja.}

\section{PEMBAHASAN}

\section{Pengembangan karir berpengaruh terhadap kepuasan kerja Perawat}

Pengembangan

karir

berpengaruh positif signifikan terhadap kepuasan kerja Perawat RSUD AWS Samarinda. Hasil penelitian ini mampu mengkonfirmasi teori (Robbins, 2008), (Flippo, 2005), (Kreitner and Kinicki, 2008) pengembangan karir mampu meningkatkan kepuasan kerja. Fakta yang ditemukan pada penelitian ini, menunjukkan adanya pengaruh positif pengembangan karir terhadap kepuasan kerja, dengan pengaruh signifikan. Secara empirik, temuan ini mendukung penelitian terdahulu yang dilakukan oleh (Nugroho and Kunartinah, 2012), (Taylor, Bradley and Nguyen, 2003), menyatakan bahwa pengembangan karir berpengaruh signifikan terhadap kepuasan kerja, namun berbeda dengan penelitian terdahulu lainnya yang dilakukan (Ekayadi, 2009), (Abbas and Azim, 2012), telah menemukan fakta empirik yang menyatakan bahwa pengembangan karir berpengaruh tidak signifikan terhadap kepuasan kerja. Fakta ini mengindikasikan bahwa pengembangan karir yang dilakukan oleh RSUD AWS Samarinda terbukti secara ilmiah mampu meningkatkan kepuasan kerja Perawat.

Kompetensi berpengaruh terhadap kepuasan kerja Perawat

Kompetensi berpengaruh positif tidak signifikan terhadap kepuasan kerja Perawat RSUD AWS Samarinda. Hasil penelitian ini belum mampu mengkonfirmasi teori (Armstrong, 2000), (Newstrom and Davis, 2007), (Robbins and Judge, 2015) kompetensi mampu meningkatkan kepuasan kerja. Fakta yang ditemukan pada penelitian ini, menunjukkan adanya pengaruh positif kompetensi terhadap kepuasan kerja, dengan pengaruh tidak signifikan. Secara empirik, temuan ini sejalan penelitian terdahulu, yang dikemukakan oleh (Wexley and Gary, 2011) menyatakan bahwa kompetensi berpengaruh tidak signifikan terhadap kepuasan kerja. Berbeda dengan penelitian terdahulu lainnya yang dilakukan oleh (Bogner and $\mathrm{H}$, 2014), (Renyut et al., 2017), (Jusmin et al., 2016) menyatakan bahwa kompetensi berpengaruh signifikan terhadap kepuasan kerja. Temuan ini mengindikasikan bahwa kompetensi yang dikembangkan oleh RSUD AWS Samarinda terbukti secara ilmiah mampu meningkatkan kepuasan kerja Perawat akan tetapi 
tidak signifikan.

\section{Pengembangan karir berpengaruh terhadap kinerja Perawat}

Pengembangan

karir

berpengaruh positif tidak signifikan terhadap kinerja Perawat RSUD AWS Samarinda. Hasil penelitian ini belum mampu mengkonfirmasi teori (Robbins, 2008), (Flippo, 2005), (Werther and Davis, 1996) pengembangan karir mampu meningkatkan kinerja. Temuan ini, menunjukkan adanya pengaruh positif pengembangan karir terhadap kinerja, dengan pengaruh tidak signifikan. Secara empirik, fakta ini mendukung penelitian terdahulu yang dilakukan oleh (Sofyan, Rahman and Nujum, 2016), (Putra and Prasetya, 2018), (Dokko, Wilk and Rothbard, 2008) menyatakan bahwa pengembangan karir berpengaruh tidak signifikan terhadap kinerja. Berbeda dengan penelitian terdahulu lainnya yang dilakukan oleh (Trivellas and Blanas, 2015), (Ansaripour et al., 2017), (Grant, 2008), (Shafiq, 2017) menyatakan bahwa pengembangan karir berpengaruh signifikan terhadap kinerja. Temuan ini mengindikasikan bahwa pengembangan karir yang dikembangkan oleh RSUD AWS Samarinda terbukti secara ilmiah belum mampu meningkatkan kinerja Perawat. Kendatipun demikian, ada kecenderungan yang positif pada hasil statistik. Hal ini tidak menutup kemungkinan jika dilakukan upayaupaya perbaikan pada suatu saat akan bisa menjadi signifikan.

\section{Kompetensi \\ berpengaruh terhadap kinerja Perawat}

Kompetensi berpengaruh positif signifikan terhadap kinerja Perawat RSUD AWS Samarinda. Hasil penelitian ini mampu mengkonfirmasi teori (Armstrong, 2000), (Schuler and Jackson, 1999), (Bernardin, 2010) kompetensi mampu meningkatkan kinerja. Fakta yang ditemukan pada penelitian ini, menunjukkan adanya pengaruh positif kompetensi terhadap kinerja, dengan pengaruh signifikan. Secara empirik, temuan ini belum mampu mendukung penelitian terdahulu yang dilakukan oleh (Ley, Dietrich and Stefanie, 2007), (Suprapto, 2009), (Zaim, 2013), menyatakan bahwa kompetensi berpengaruh tidak signifikan terhadap kinerja. Berbeda dengan penelitian terdahulu lainnya yang dilakukan oleh (Winanti, 2011), (Sriwidodo and Agus, 2010), menyatakan bahwa kompetensi berpengaruh signifikan terhadap kinerja. (Winanti, 2011) dalam penelitiannya menyimpulkan bahwa kompetensi berpengaruh terhadap kinerja SDM. (Sriwidodo and Agus, 2010) mengemukakan pendapatnya bahwa kinerja dan keefektifan pegawai dalam melaksanakan tugas sangat ditentukan oleh kompetensi yang disyaratkan oleh bidang pekerjaan.

Kepuasan kerja berpengaruh terhadap kinerja Perawat

Kepuasan kerja berpengaruh positif signifikan terhadap kinerja Perawat RSUD AWS Samarinda. Dengan demikian, hipotesis kedua 
belas diterima. Hasil penelitian ini mampu mengkonfirmasi teori (Luthans, 2002), (Gibson, 2008), (Wexley and Gary, 2011), (Bernardin, 2010), (Mc.Clelland, 1997), (Mathis and Jackson, 2006), (Gibson, 2008) yang menyebutkan bahwa kepuasan kerja mampu meningkatkan kinerja. Fakta ini mendukung penelitian terdahulu yang dilakukan oleh (Palagia, Brasit and Amar, 2010), (Jahangir, 2004), (Kristensen and Nielsen, 2004), menyatakan bahwa kepuasan berpengaruh signifikan terhadap kinerja. Berbeda dengan penelitian terdahulu lainnya yang dilakukan (Brouwers and Tomic, 2000), (Caprara et al., 2003), (Malone, 2006), (Greenglass and Burke, 2003), menyatakan bahwa kepuasan berpengaruh tidak signifikan terhadap kinerja.

\section{Pengembangan karir berpengaruh terhadap kinerja melalui kepuasaan kerja.}

Pengembangan karir terhadap kinerja melalui kepuasan kerja memberikan pengaruh positif dan signifikan hal ini mempunyai arti bahwa kepuasan telah mampu menjadi variabel mediasi dalam perannya meningkatkan pengaruh penggembangan karir terhadap kinerja. Pengembangan karir dengan indikator tertingginya yaitu penilaian pekerjaan yang baik dalam memperoleh pengembangan karir $\left(X_{1.2}\right)$ telah mampu meningkatkan kinerja perawat dengan indikator tertinggi pengetahuan perawat tersebut dalam menyelesaikan pekerjaan telah sesuai dengan harapan rumah sakit $\left(\mathrm{Y}_{2.3}\right)$ nilai pengaruh tersebut akan semakin baik apabila ditambahkan variabel kepuasan dengan indikator tertinggi puas dengan hubungan pekerjaan dengan atasan ( $\left.\mathrm{Y}_{1.4}\right)$, sehingga dalam penelitian ini dapat diketahui bahwa kepuasa kerja telah mampu menjadi variabel mediasi karena mampu menjalankan perannya dalam meningkatkan kinerja pegawai dengan pengembangan karir sebagai variabel yang mempengaruhinya.

\section{KESIMPULAN DAN SARAN}

Berdasarkan hasil analisis maka dapat diambil kesimpulan sebagai berikut: 1) pengembangan karir berpengaruh positif dan signifikan terhadap kepuasan kerja Perawat RSUD AWS Samarinda. 2) kompetensi berpengaruh positif dan tidak signifikan terhadap kepuasan kerja Perawat RSUD AWS Samarinda. 3) pengembangan karir berpengaruh positif dan tidak signifikan terhadap kinerja Perawat RSUD AWS Samarinda. 4) kompetensi berpengaruh positif dan signifikan terhadap kinerja Perawat RSUD AWS Samarinda 5) kepuasan kerja berpengaruh positif dan signifikan terhadap kinerja Perawat RSUD AWS Samarinda 6) pengembangan karir berpengaruh positif dan signifikan terhadap kinerja melalui kepuasan kerja Perawat RSUD AWS Samarinda 
Berdasarkan kesimpulan maka dapat diambil saran sebagai berikut: 1. RSUD AWS Samarinda diharapkan mempunyai penilaian pekerjaan yang baik sesuai dengan aturan yang telah ditetapkan bagi Perawat, sehingga Perawat mampu mencapai pengembangan karir yang optimal, yang pada akhirnya berdampak pada tingkat efisiensi, kualitas kerja yang dicapai, baik secara individu maupun kolektif yang sesuai dengan harapan RSUD AWS Samarinda.

2. RSUD AWS Samarinda diharapkan mempunyai sistem pengembangan karir yang terstruktur sesuai dengan pencapaian kinerja perawat secara terukur sehingga perawat mempunyai acuan yang jelas untuk dapat memberikan kinerjanya secara optimal demi mencapai pengembangan karir sesuai dengan kebutuhan perawat.

3. RSUD AWS Samarinda diharapkan terus melakukan perbaikan secara berkala yang dilakukan bersama-sama dengan Perawat mengenai optimalisasi pencapaian kompetensi Perawat baik secara individual maupun kolektif agar tercapai tujuan RSUD AWS Samarinda.

\section{RSUD AWS Samarinda} diharapkan memberikan pelatihan yang sesuai dengan kebutuhan rumah sakit secara spesifik berupa pengenalan lingkungan rumah sakit, karakteristik pasien di rumah sakit dan lingkungan kerja di rumah sakit, sehingga perawat mampu memberikan kompetensi yang optimal dalam mencapai kinerjanya.

5. RSUD AWS Samarinda diharapkan agar memberikan penilaian yang adil dan objektif terhadap kualitas kerja Perawat sehingga mendorong kepuasan Perawat terhadap hubungan dengan atasannya.

6. RSUD AWS Samarinda diharapkan mampu meningkatkan dan mempertahankan kepuasan kerja perawat dalam hubungannya sebagai variabel perantara dalm hal ini adalah variabel pengembangan kariri dan kompetensi dalam meningkatkan kinerja perawat.

\section{UCAPAN TERIMA KASIH}

Ucapan terima kasih penulis sampaikan kepada Direktur RSUD AWS Samarinda yang telah memberikan izin penelitian, ucapan terima kasih juga penulis sampaikan kepada seluruh responden dalam penelitian yaitu perawat RSUD AWS Samarinda yang telah memberikan waktunya untuk mengisi kuesioner dalam penelitian ini.

\section{DAFTAR PUSTAKA}

Abbas, A. and Azim, Z. (2012) 'The Link Between Workplace Spirituality, Organizational Citizenship Behavior And Job Performance In Iran. A Journal of Economics and 
Management.', A Journal of Economics and Management, 1(6, September 2012, ISSN 2278-0629), pp. 51-67.

Ansaripour, S. et al. (2017) 'The Role of Job Performance on Career Success and Self-esteem of Staff', Journal of Clinical and Diagnostic Research, Oct, Vol1.

Armstrong, M. (2000) Manajemen Sumber Daya Manusia, A Handbook of Human Resources Management. Edited by A. Dharma. Jakarta: PT. Elex Media Komputindo.

Bernardin, R. (2010) Human Resources Management. New York: Mc Graw Hill.

Bogner, W. C. and H, T. (2014) Core Competences and Competitive Advantage: A Model and Illustrative Evidence from Pharmaceutical Industry. New York: John Wiley and Sons.

Brouwers, A. and Tomic, W. (2000) 'A longitudinal study of teacher burnout and perceived selfeficacy in classroom management', Teaching and Teacher Education 16 (2000) $239\} 253$.

Caprara, G. V. et al. (2003) 'Efficacy Beliefs as Determinants of Teachers' Job Satisfaction', Journal of Educational Psychology, 95 (4):821.

Dokko, G., Wilk, S. and Rothbard, N. (2008) 'Unpacking prior experience: How career history affects job performance? Organization Science', 20(1),
51-68.

Ekayadi, S. (2009) 'Pengaruh Motivasi Dan Pengembangan Karir Terhadap Kepuasan Kerja Karyawan Pada PT. Rimbajatiraya Citrakarya', Jurnal Fakultas Ekonomi Universitas Gunadarma Jakarta.

Flippo, E. B. (2005) Manajemen Personalia Edisi Keenam. Edited by A. S.Raja. Jakarta: Grafindo.

Gibson, I. (2008) Organisasi. Edited by A. Dharma. Jakarta: Binarupa Aksara.

Grant, R. M. (2008) 'Toward a knowledge-based theory of the firm', Strategic Management Journal, 17: 109.

Greenglass, E. and Burke, R. (2003) 'Teacher stress. In M. F. Dollard, A. H. Winefield, \& H. R. Winefield', Occupational stress in the service professions ( $p p$. 213-236). New York: Taylor \& Francis.

Jahangir, N. (2004) 'Organizational Citizenship Behavior: Its Nature And Antecedents', BRAC University Journal, vol. I, no. 2, 2004, pp. 75-85.

Jusmin, A. et al. (2016) 'Specific Determinants of Work Motivation, Competence, Organizational Climate, Job Satisfaction and Individual Performance: A Study among Lecturers', Journal of Business and Management Sciences 4, no. 3 (2016): 53-59.

Kreitner, R. and Kinicki, A. (2008) 
Organization Behaviour. New York: McGraw-Hill Higher Education.

Kristensen, M. and Nielsen, J. (2004) 'Satisfaction and Human', Journal of Physiology.

Ley, T., Dietrich, A. and Stefanie, L. (2007)

'Competency

Management Using The Competence Performance Approach: Modeling, Assessment, Validation, And Use', ttp:// www.ideagroup.com.

Luthans, F. (2002) Organizations Behavior. Edited by J. E. Biernat. New York:McGraw Hill International.

Malone, T. (2006) 'Do Some Business Models Perform Better than Others?', MIT Sloan School of Management MIT Sloan Working Paper 4615-06 May 2006.

Mathis, R. and Jackson, H. (2006) Manajemen Sumber Daya Manusia. Edited by S. dan Bayu. Jakarta: Salemba Empat. Mc.Clelland, D. C. (1997) Human motivation. Edited by F. Glenview, IL: Scott.

Newstrom, J. I and Davis, K. (2007) Organizational

Behavior: Human Human Behavior at work. New York: McGraw-Hill.

Nugroho and Kunartinah (2012)

'Analisis

Pengaruh

Kompensasi

Dan

Pengembangan Karier

Terhadap Kepuasan Kerja

Dengan Mediasi Motivasi Kerja (Studi Pada Pns Di Sekretariat
Daerah Kabupaten

Pekalongan)', Jurnal Bisnis dan Ekonomi (JBE), September 2012, Hal. 153 - 169. Vol. 19, No. 2 ISSN: 1412-3126 153.

Palagia, M., Brasit, N. and Amar, M. (2010) 'Remunerasi, Motivasi dan Kepuasan Kerja serta Kinerja Karyawan', Jurnal Manajemen, 1-10.

Putra, S. S. and Prasetya (2018) 'The Influence of Reward, WorkPlace Environment, And Career Growth to Job Satisfaction and Their Impact on Organizational Commitment', Jurnal Administrasi Bisnis (JAB)|Vol. 64 No. 1 November 2018| administrasibisnis. studentjourn al.ub.ac.id.

Renyut, B. C. et al. (2017) 'The effect of organizational commitment, competence on Job satisfaction and employee performance in Maluku Governor's Office', IOSR Journal of Business and Management (IOSR-JBM) eISSN: 2278-487X, p-ISSN: 2319-7668. Volume 19, Issue 11. Ver.III (November. 2017), PP 18-29 www.iosrjournals.org. Robbins, S. (2008) Organizational Behavior: Concept, Controversies, Aplications. Edisi 8. Edited by D. Angelica and R. Cahyani. Jakarta: PT. Indeks Kelompok Gramedia.

Robbins, S. and Judge, T. (2015) Perilaku Organisasi (Organizational Behavior). Edited by R. Saraswati and F. 
Sirait. Pearson Education, Inc New Jersey Authirozed Translation Salemba Empat. Jakarta.

Schuler, R. and Jackson, S. (1999) Human Resource Management: Positioning for the 21st century. Minneapolis: West Pub.Co.

Shafiq, S. (2017) 'The Effect of Training and Development on Employee Performance In Private Company, Malaysia', International Journal of Education, Learning and Training Vol. 2 (No.2), November 2017 ISSN: 22896694 DOI: 24924/ijelt/2017.04/v2.iss2/42. 56.

Sofyan, M., Rahman, A. and Nujum, S. (2016) 'The Effect of Career Development And Working Discipline Towards Working Satisfaction And Employee Performance In The Regional Office Of Ministry Of Religious Affairs In South Sulawesi', International Journal Of Scientific and Technology Research Volume 5, Issue 03, March 2016.

Sriwidodo, U. and Agus, B. H. (2010) 'Pengaruh Kompetensi, Motivasi, Komunikasi Dan Kesejahteraan Terhadap Kinerja Pegawai Dinas Pendidikan', Jurnal Manajemen Sumber Daya Manusia, 4(1): h:47-57.

$\begin{array}{cr}\text { Suprapto (2009) } & \text { 'Pengaruh } \\ \text { Kompetensi } & \text { Dan }\end{array}$

Terhadap Kinerja Pegawai

Dengan Kepuasan Sebagai Moderating Variabel', Excellent, 1(1): $h: 1-19$.

Taylor, J., Bradley, S. and Nguyen, A. (2003) 'Job autonomy and job satisfaction: new evidence', Working Papers.

Trivellas, K. and Blanas, S. (2015) 'Demography and diversity in organizations: a review of 40 years of research. In: Staw BM', Research in organizational behavior, Vol. 20. Greenwich: JAl Press.

Werther, W. and Davis, K. (1996) Human Resources and Personal Management. New York: McGraw Hill. Inc.

Wexley, K. N. and Gary, A. Y. (2011) Perilaku Organisasi Dan Psikolog. Jakarta : Indeks.

Winanti, M. B. (2011) 'Pengaruh Kompetensi terhadap Kinerja Karyawan (Survei pada PT. Frisian Flag Indonesia Wiayah Jawa Barat)', Majalah IImiah UNIKOM Vol. 7 No. 2, 249- 267.

Zaim, H. (2013) 'Analyzing the Effects of Individual Competencies On Performance: A Field Study In Services Industries In Turkey', publication at: https:// www.researchgate.net/ publication/ 292674651. 